\title{
Perbandingan Berat Material Baja Pada Perencanaan Struktur Baja Sistem Rangka Pengaku Eksentris (SRPE) dengan Sistem Staggered Truss Frames (STF) pada Apartemen Purimas Surabaya
}

\author{
Ilham Pratama Budiono, Endah Wahyuni dan Isdarmanu \\ Departemen Teknik Sipil, Fakultas Teknik Sipil \& Perencanaan, Institut Teknologi Sepuluh Nopember (ITS) \\ e-mail:endah@ce.its.ac.id
}

\begin{abstract}
Abstrak-Pemilihan suatu sistem struktur baja penahan gempa tentunya memerhatikan bagaimana cara membuat struktur bangunan baja menjadi ringan dan kuat. Sistem rangka pengaku eksentris (SRPE) dan staggered truss frames (STF) merupakan beberapa contoh dari sistem penahan gempa pada struktur baja. Apartemen Purimas Surabaya merupakan bangunan 14 lantai yang dimodifikasi dengan menggunakan SRPE dan STF untuk dibandingkan berat material struktur utamanya pada kedua sistem tersebut. Dalam Studi ini, dilakukan perencanaan struktur baja dengan SRPE meliputi perencanaan struktur sekunder, primer dan pondasi yang mengacu pada PPIUG 1983, SNI 03-1729-2002, SNI 1729:2015, SNI 1726:2012, SNI 2847:2013 dan lain-lain. Berat material sturktur hasil dari perencanaan tersebut dibandingkan dengan hasil perencanaan STF pada studi "Studi Perilaku Staggered Truss Framing Systems pada Gedung Apartemen Purimas Surabaya". Berdasarkan analisis dan hasil perhitungan diperoleh hasil, yaitu: pelat atap dan lantai $\mathrm{HCS} 15 \mathrm{~cm}$, balok link WF400.200.8.13, bresing WF200.200.9.14, kolom CFT 400.400.14, balok induk WF300.200.7.10. Sambungan struktur utama direncanakan sebagai sambungan mutu tinggi dengan baut yang telah disesuaikan. Perencanaan pondasi menggunakan tiang pancang beton pracetak diameter $60 \mathrm{~cm}$ dengan kedalaman $30 \mathrm{~m}$ dengan 3 tipe pilecap. Berat material struktur utama pada SRPE sebesar 1105 ton, sedangkan pada STF didapatkan 763 ton.
\end{abstract}

Kata Kunci-Struktur Baja, Gempa, Sistem Rangka Pengaku Eksentris, Staggered Truss Frames, Bangunan Apartemen.

\section{PENDAHULUAN}

$\mathrm{G}$ EMPA tektonik merupakan guncangan dari dalam bumi baik di darat maupun laut yang diakibatkan karena adanya pergeseran lempeng tektonik secara mendadak. Gempa tektonik memiliki resiko besar pada suatu daerah yang dilewati oleh lempeng tektonik. Indonesia berada pada pertemuan tiga lempeng tektonik terbesar di dunia yaitu Indo-Australia, Eurasia, dan Pasifik yang bergerak dan saling mendesak satu sama lain. Indonesia telah mengalami ribuan gempa bumi dan ratusan tsunami pada rentang empat ratus tahun terakhir [1]. Sebagai contoh gempa tektonik terbesar yang terjadi di beberapa daerah Indonesia hingga saat ini adalah gempa bumi Aceh dan Sumatera Utara yang diikuti dengan tsunami terjadi pada Desember 2004, dan gempa bumi Sumatera Barat terjadi pada September 2009. Semua gempa yang terjadi tersebut menimbulkan ribuan korban jiwa, kerugian materiil, dan bangunan mengalami rusak berat.

Perencanaan bangunan tahan gempa sangat penting diterapkan di Indonesia yang merupakan salah satu daerah dengan resiko bencana gempa yang cukup besar dalam beberapa dekade mendatang. Dengan adanya perencanaan bangunan tahan gempa tersebut, maka diharapkan dapat mencegah kegagalan struktur, bahkan jumlah korban jiwa ketika gempa terjadi. Oleh karena itu, dalam merencanakan bangunan tahan gempa harus mengutamakan keselamatan dan kenyamanan orang yang berada pada bangunan tersebut. Material dan sistem struktur merupakan hal utama yang diperlukan dalam perencanaaan konstruksi bangunan tahan gempa.

Pada perencanaan struktur bangunan baja terdapat berbagai macam sistem struktur pemikul beban / gempa pada gedung bertingkat yang digunakan diantaranya adalah Sistem Rangka Pengaku Eksentris (SRPE) dan Staggered Truss Frame (STF). Pada studi perencanaan dan perbandingan ini akan dilakukan modifikasi pada struktur gedung apartemen Purimas Surabaya. Gedung yang sebelumnya dimodifikasi dengan menggunakan sistem struktur Staggered Truss Frame (STF) pada studi "Studi Perilaku Staggered Truss Framing Systems pada Gedung Apartemen Purimas Surabaya", akan direncanakan dengan menggunakan sistem rangka pengaku eksentris (SRPE).

Tujuan dari studi ini adalah merencanakan struktur bangunan baja dengan sistem Sistem Rangka Pengaku Eksentris (SRPE) meliputi perencanaan struktur utama, sekunder, dan pengaku yang sesuai dengan pembebanan bangunan tahan gempa. Adanya perencanaan sistem struktur Sistem Rangka Pengaku Eksentris (SRPE) kemudian dibandingkan dengan sistem struktur Staggered Truss Frame (STF) dari hasil penelitian sebelumnya maka didapat berat total struktur utama apartemen Purimas Surabaya yang paling minimum.

\section{TINJAUAN PUSTAKA}

Beban gempa yang akan ditanggung oleh struktur atau elemen struktur tidak selalu dapat diramalkan dengan tepat sebelumnya, maka dalam tahap perencanaan, seorang perencana dituntut untuk dapat memahami perancangan struktur tahan gempa dalam mendesain bangunan. 


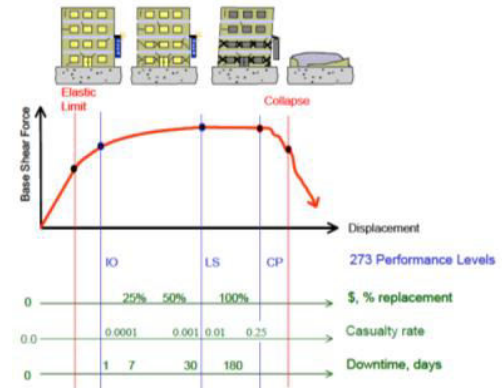

Gambar 1. Ilustrasi Rekayasa Gempa Berbasis Kinerja (Sumber: ATC 58)

Sistem struktur SRPE merupakan struktur baja penahan gaya lateral yang merupakan gabungan antara konsep daktilitas dan disipasi energi yang baik dari desain MomentResisting Frames (MRF) dengan karakteristik kekakuan elastik yang tinggi dari desain Concentrically Braced Frames (CBF). SRPE memiliki elastisitas tinggi, respons inelastis stabil pada muatan lateral siklis, daktilitas dan kapasitas disipasi energi yang besar [2].

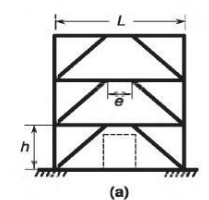

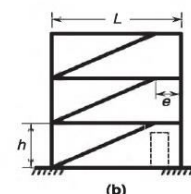

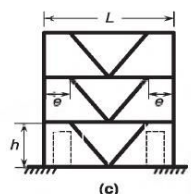

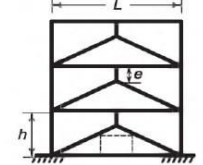

(d)

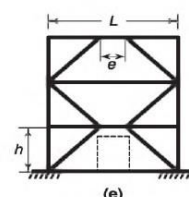

Gambar 2. Tipe Konfigurasi SRPE

(Sumber: Bruneau,1998)

Gaya yang terjadi pada Gambar 3 menunjukkan free-body diagram dari sebuah link. Dengan mengabaikan gaya aksial yang terjadi dan interaksi antara momen dan geser pada link, kedua momen tumpuan Ma dan Mb telah mencapai keadaan plastis, Mp. Gaya geser pada tumpuan juga dalam keadaan plastis, Vp. Momen plastis dan kapasitas geser pada link tersebut dapat dirumuskan sebagai berikut :

$$
\begin{aligned}
& M_{p}=Z_{x} \cdot f_{y} \\
& V_{p}=\tau_{y} A_{l w}
\end{aligned}
$$

Keterangan:

$\mathrm{M}_{\mathrm{p}}=$ Momen plastis penampang

$\mathrm{Z}_{\mathrm{x}} \quad=$ Modulus plastis penampang

$\mathrm{f}_{\mathrm{y}} \quad=$ Tegangan leleh penampang

$\tau_{\mathrm{y}} \quad=0,6 \mathrm{~F}_{\mathrm{y}}(\mathrm{AISC} 2010) ; 0,55 \mathrm{~F}_{\mathrm{y}}(\mathrm{CSA} 2009)$

$\mathrm{A}_{\mathrm{lw}}=\left(\mathrm{d}-2 \mathrm{t}_{\mathrm{f}}\right) \cdot \mathrm{t}_{\mathrm{w}}$, untuk bentuk -I

$=2\left(\mathrm{~d}-2 \mathrm{t}_{\mathrm{f}}\right) \cdot \mathrm{t}_{\mathrm{w}}$, untuk bentuk penampang boks

$\mathrm{V}_{\mathrm{p}} \quad$ = Gaya geser plastis penampang

$\mathrm{d} \quad=$ Tinggi penampang

$\mathrm{t}_{\mathrm{f}} \quad=$ Tebal flens

$\mathrm{t}_{\mathrm{w}} \quad=$ Tebal $w e b$

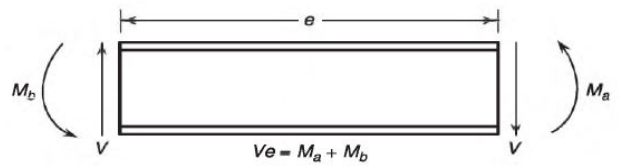

Gambar 3. Free body Diagram dan gaya pada Link.
(Sumber: Bruneau,1998)

Sistem Staggered Truss Framing (STF) atau kerangka batang tersusun secara berselang-seling awalnya dikembangkan oleh Massachussetts Institute Of Technology (MIT). Sistem Staggered Truss Framing menjadi efektif apabila digunakan untuk bangunan dengan tinggi menengah yaitu antara 5 sampai 25 lantai, contohnya apartemen, hotel, motel, rumah sakit, serta struktur lain yang menggunakan tinggi antar lantai yang rendah [3]. Bentuk STF dapat dilhat pada Gambar 4 [4].

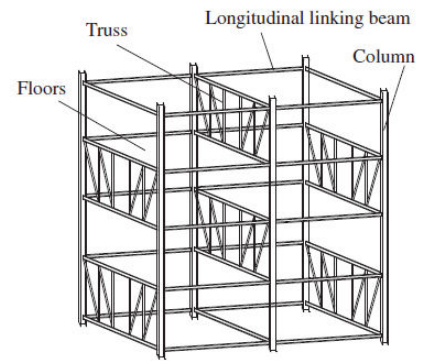

Gambar 4. Staggered Truss Framing Systems (Sumber : Zhou dkk, 2008).

\section{METODOLOGI}

Urutan penyelesaian Studi ini dapat dilihat pada bagan alir dibawah ini:

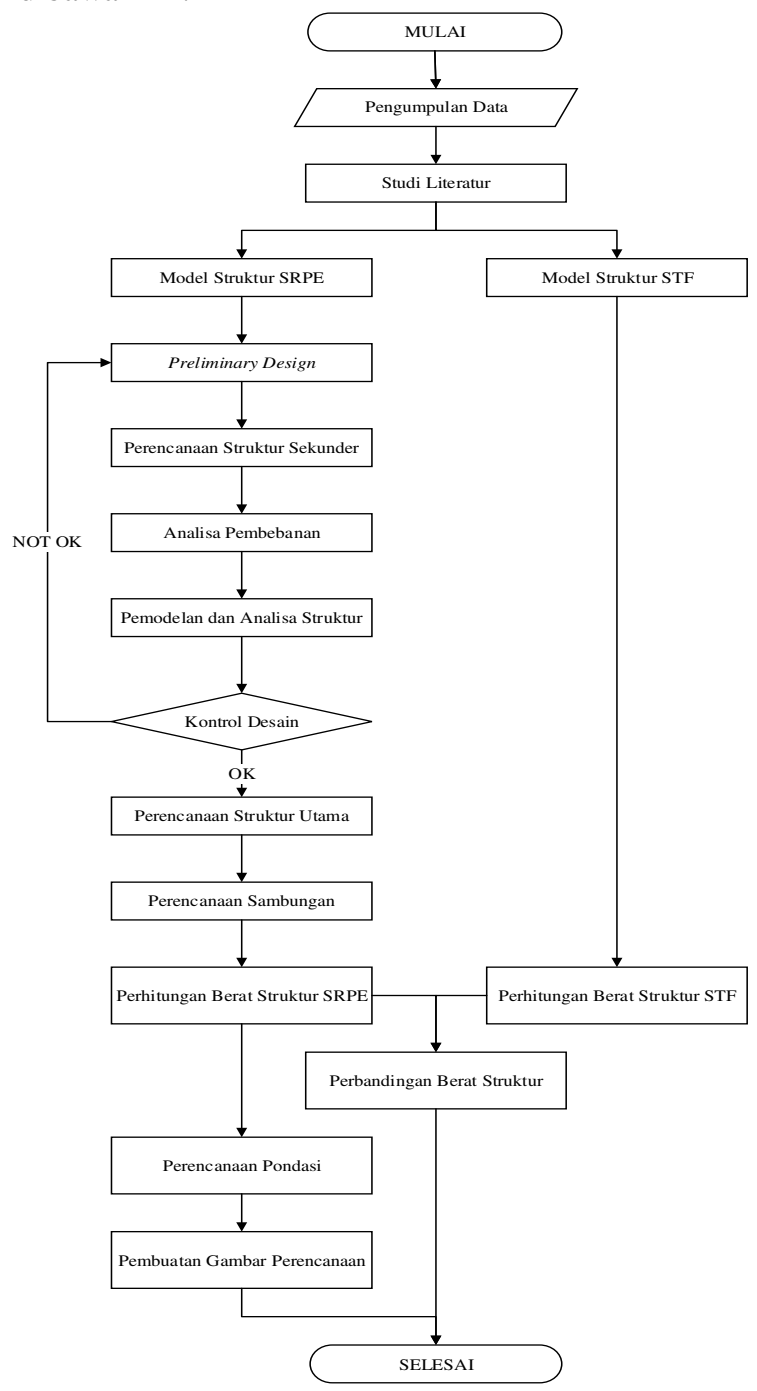

Gambar 5. Diagram Alir Penyelesaian Studi. 
Direncanakan sebuah gedung perkantoran 26 lantai dengan data- data sebagai berikut:

$\begin{array}{ll}\text { Nama gedung } & : \text { Apartemen Purimas } \\ \text { Lokasi } & : \\ \text { Fungsi gedung } & : \text { Gedung Apartemen } \\ \text { Panjang gedung } & : 44 \mathrm{~m} \\ \text { Lebar gedung } & : 13,85 \mathrm{~m} \\ \text { Jumlah tingkat } & : 14 \text { tingkat } \\ \text { Tinggi gedung } & : 43,3 \mathrm{~m} \text { (13 lantai + atap) } \\ \text { Tinggi lantai dasar } & : 4,3 \mathrm{~m} \\ \text { Tinggi antar lantai } & : 3 \mathrm{~m} \\ \text { Zona gempa } & : 3 \\ \text { Struktur utama } & : \text { baja Sistem Rangka Pengaku } \\ & \text { Eksentris (SRPE), komposit } \\ & \text { baja dan beton (kolom) } \\ \text { Pelat atap \& lantai } & : \text { Prestressed Precast Concrete } \\ & \text { tipe Hollow Core Slab } \\ \text { Mutu beton (f'c) } & : 45 \mathrm{MPa} \\ \text { Mutu baja } & : \text { BJ } 41\end{array}$

\section{PERENCANAAN STRUKTUR SEKUNDER}

\section{A. Pelat Atap dan Pelat Lantai}

Pelat lantai atap dan lantai perkantoran direncanakan menggunakan pelat beton pracetak pratekan Hollow Core Slab dengan lebar $1200 \mathrm{~mm}$. Hasil perhitungan struktur pelat ini tersaji pada Tabel 1 .

Tabel 1.

Dimensi dan Penulangan Pelat

\begin{tabular}{ccccc}
\hline \hline $\begin{array}{c}\text { Elemen } \\
\text { Pelat }\end{array}$ & $\begin{array}{c}\text { Beban } \\
\text { Berguna } \\
\left(\mathrm{kg} / \mathrm{m}^{2}\right)\end{array}$ & $\begin{array}{c}\text { Bentang } \\
(\mathrm{m})\end{array}$ & $\begin{array}{l}\text { Tebal } \\
\text { Pelat } \\
(\mathrm{cm})\end{array}$ & $\begin{array}{l}\text { Tulangan } \\
\text { PC Wire }\end{array}$ \\
\hline Atap & 286 & 6 & 15 & $14 \emptyset 5$ \\
Lantai & 415 & 6 & 15 & $16 \emptyset 5$ \\
\hline \hline
\end{tabular}

Tabel 2.

Dimensi Tangga

\begin{tabular}{|c|c|}
\hline Elemen & Profil / Material yang Digunakan \\
\hline Pelat Anak Tangga & $\begin{array}{c}\text { Bondek SUPER FLOOR DECK, tebal plat } \\
=9 \mathrm{~cm} \text {, tanpa tulangan negatif }\end{array}$ \\
\hline Pelat Bordes & $\begin{array}{l}\text { Bondek SUPER FLOOR DECK, tebal plat } \\
\quad=9 \mathrm{~cm} \text {, tulangan negatif } \varnothing 10-300\end{array}$ \\
\hline Balok Utama Tangga & WF $200 \times 150 \times 6 \times 9$ \\
\hline $\begin{array}{l}\text { Balok Penumpu } \\
\text { Tangga }\end{array}$ & WF $200 \times 150 \times 6 \times 9$ \\
\hline
\end{tabular}

B. Perencanaan Tangga dan Bordes

Tangga adalah sebuah konstruksi yang dirancang untuk menghubungi dua tingkat vertikal yang memiliki jarak satu sama lain.

Data Teknis Tangga:

- Mutu baja (BJ-41) :

fy

fu

- Tinggi antar lantai

- Tinggi bordes (y)

- Panjang tangga (x)

- Lebar tangga

- Lebar bordes

- Lebar injakan (i)

- Lebar pegangan tangga

- Tinggi injakan (t)

- Jumlah tanjakan (n)

- Jumlah injakan

\section{Perencanaan Balok Penggantung Lift}

Balok Penggantung Lift direncanakan menerima beban dari lift penumpang berdasarkan spesifikasi pada brosur sebagai berikut:

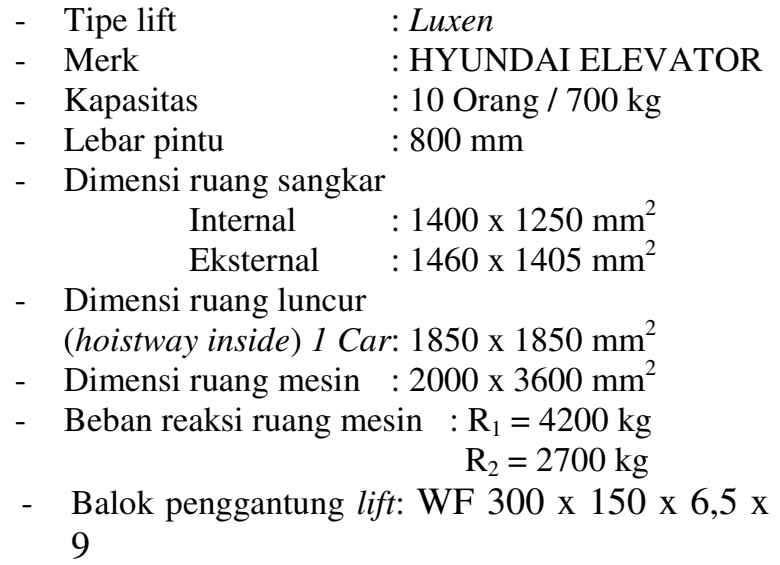

\section{KONTROL HASIL ANALISIS STRUKTUR}

\section{A. Kontrol Partisipasi Massa}

Partisipasi massa harus menyertakan jumlah ragam terkombinasi minimal $90 \%$ dari massa aktual yang berasal dari masing-masing arah horizontal dan orthogonal yang ditinjau [5].

Tabel 3.

Kontrol Nilai Partisipasi Massa

\begin{tabular}{ccccc}
\hline \hline OutputCase & Steptype & StepNum & SumUX & Sum UY \\
\hline Text & Text & Unitless & Unitless & Unitless \\
Modal & Mode & 4 & 0.904 & 0.747 \\
Modal & Mode & 5 & 0.904 & 0.908 \\
\hline \hline
\end{tabular}

\section{B. Kontrol Waktu Getar Alami Fundamental}

Perkiraan periode alami fundamental (Ta) dalam detik, harus ditentukan dengan persamaan berikut:

$\mathrm{Ta}=\mathrm{Ct} . \mathrm{hn}^{\mathrm{x}} ; \mathrm{Ct}=0,0731 ; \mathrm{x}=0,75 ; \mathrm{hn}=43.3 \mathrm{~m}$

$\mathrm{Ta}=0,0731.43 \cdot 3^{0,75}=1.234$ detik

Dengan nilai $\mathrm{SD} 1=0,5$, maka $\mathrm{Cu}=1,4$

Sehingga periode sruktur yang diijinkan adalah :

$\mathrm{T}=\mathrm{Ta} . \mathrm{Cu}=1.234 .1,4=1.73$ detik

Tabel 4.

Kontrol Waktu Getar Alami Fundamental

TABLE: Modal Periods And Frequencies

\begin{tabular}{ccccc} 
OutputCase & StepType & StepNum & Period & Frequency \\
\hline Text & Text & Unitless & Sec & Cyc/sec \\
MODAL & Mode & 1 & 1.71 & 0.437 \\
MODAL & Mode & 2 & 1.51 & 0.473 \\
MODAL & Mode & 3 & 1.45 & 0.687 \\
MODAL & Mode & 4 & 0.75 & 1.329 \\
MODAL & Mode & 5 & 0.25 & 1.442 \\
MODAL & Mode & 11 & 0,24 & 4.083 \\
MODAL & Mode & 12 & 0,2 & 5.037
\end{tabular}

Dari tabel tersebut didapat periode maksimum $\mathrm{Tc}=1.73$ detik. Maka berdasarkan kontrol waktu getar alami fundamental nilai periode tersebut lebih besar dari periode 
struktur yang diijinkan $\left(\mathrm{T}_{\mathrm{c}}<\mathrm{C}_{\mathrm{u}} \cdot \mathrm{T}_{\mathrm{a}}\right)$. Jadi, analisis struktur apartemen Purimas Surabaya menggunakan $\mathrm{T}=1.71$ detik.

\section{Kontrol Nilai Akhir Respon Spektrum}

Kombinasi respons untuk gaya geser dasar ragam dinamik (Vt) harus lebih besar $85 \%$ dari gaya geser dasar statik $(\mathrm{V})$ atau $\left(\mathrm{V}_{\text {dinamik }} \geq 0,85 \mathrm{~V}_{\text {statik }}\right)[5]$.

Tabel 5.

Kontrol Nilai Akhir Respon Spektrum

\begin{tabular}{llcc}
\hline \hline Ket & $\mathrm{V}_{\text {dinamik }}(\mathrm{kg})$ & $\mathrm{V}_{\text {statik }}(\mathrm{kg})$ & $\mathrm{V}_{\text {dinamik }} \geq \mathrm{V}_{\text {statik }}$ \\
\hline RSX & 187128.5 & \multirow{2}{*}{196224.52} & Not OK \\
RSY & 199303.5 & & OK \\
\hline \hline
\end{tabular}

Karena hasil pada arah $\mathrm{X}$ tidak memenuhi maka simpangan antar lantai harus diperbesar dengan faktor skala $0,85 \frac{\text { Cs.W }}{v}$.

Untuk simpangan arah $\mathrm{X}$ harus dikalikan:

$0,85 \frac{\text { Cs. } W}{v}=0,85 \times \frac{0,027 \times 8550088}{187128.5}=1.04$

\section{Kontrol Simpangan (Drift)}

Gempa menyebabkan struktur bertingkat rawan terhadap terjadinya simpangan horizontal (Drift). Dan apabila simpangan horizontal ini melebihi syarat aman yang telah ditentukan maka gedung akan mengalami keruntuhan [5].

Tabel 6.

Kontrol Simpangan Arah-X Gempa Arah X

\begin{tabular}{|c|c|c|c|c|c|c|c|}
\hline \multirow{2}{*}{ Lantai } & hi & Sex & $\delta x$ & $\Delta$ & $\Delta \mathrm{a}$ & $\Delta \mathrm{a} / \rho$ & Cek \\
\hline & $(\mathrm{mm})$ & $(\mathrm{mm})$ & $(\mathrm{mm})$ & $(\mathrm{mm})$ & $(\mathrm{mm})$ & $(\mathrm{mm})$ & $\Delta \leq \Delta a / \rho$ \\
\hline 14 (Atap) & 3000 & 50.9 & 203.6 & 9.6 & 60 & 60 & OK \\
\hline 13 & 3000 & 48.5 & 194 & 12 & 60 & 60 & OK \\
\hline 12 & 3000 & 45.5 & 182 & 13.2 & 60 & 60 & OK \\
\hline 11 & 3000 & 42.2 & 168.8 & 14.4 & 60 & 60 & OK \\
\hline 10 & 3000 & 38.6 & 154.4 & 15.6 & 60 & 60 & OK \\
\hline 9 & 3000 & 34.7 & 138.8 & 15.6 & 60 & 60 & OK \\
\hline 8 & 3000 & 30.8 & 123.2 & 16 & 60 & 60 & OK \\
\hline 7 & 3000 & 26.8 & 107.2 & 16.4 & 60 & 60 & OK \\
\hline 6 & 3000 & 22.7 & 90.8 & 16.4 & 60 & 60 & OK \\
\hline 5 & 3000 & 18.6 & 74.4 & 16 & 60 & 60 & OK \\
\hline 4 & 3000 & 14.6 & 58.4 & 15.2 & 60 & 60 & OK \\
\hline 3 & 3000 & 10.8 & 43.2 & 15.2 & 60 & 60 & OK \\
\hline 2 & 3000 & 7 & 28 & 14.4 & 60 & 60 & OK \\
\hline 1 & 4300 & 3.4 & 13.6 & 13.6 & 86 & 86 & OK \\
\hline
\end{tabular}

Tabel 7.

Kontrol Simpangan Arah-Y Gempa Arah Y

\begin{tabular}{|c|c|c|c|c|c|r|c|}
\multicolumn{10}{c|}{ Kontrol Simpangan Arah-Y Gempa Arah Y } \\
\hline \multirow{2}{*}{ Lantai } & $\mathbf{h i}$ & $\mathbf{\delta e x}$ & $\mathbf{\delta x}$ & $\boldsymbol{\Delta}$ & $\boldsymbol{\Delta a}$ & $\boldsymbol{\Delta a} / \mathbf{p}$ & Cek \\
\cline { 2 - 8 } & $\mathbf{( m m )}$ & $\mathbf{( m m )}$ & $\mathbf{( m m )}$ & $\mathbf{( m m )}$ & $\mathbf{( m m )}$ & $\mathbf{( m m )}$ & $\boldsymbol{\Delta} \leq \mathbf{\Delta} / \mathbf{p}$ \\
\hline 14 (Atap) & 3000 & 50.9 & 203.6 & 9.6 & 60 & 60 & OK \\
\hline 13 & 3000 & 48.5 & 194 & 12 & 60 & 60 & OK \\
\hline 12 & 3000 & 45.5 & 182 & 13.2 & 60 & 60 & OK \\
\hline 11 & 3000 & 42.2 & 168.8 & 14.4 & 60 & 60 & OK \\
\hline 10 & 3000 & 38.6 & 154.4 & 15.6 & 60 & 60 & OK \\
\hline 9 & 3000 & 34.7 & 138.8 & 15.6 & 60 & 60 & OK \\
\hline 8 & 3000 & 30.8 & 123.2 & 16 & 60 & 60 & OK \\
\hline 7 & 3000 & 26.8 & 107.2 & 16.4 & 60 & 60 & OK \\
\hline 6 & 3000 & 22.7 & 90.8 & 16.4 & 60 & 60 & OK \\
\hline 5 & 3000 & 18.6 & 74.4 & 16 & 60 & 60 & OK \\
\hline 4 & 3000 & 14.6 & 58.4 & 15.2 & 60 & 60 & OK \\
\hline 3 & 3000 & 10.8 & 43.2 & 15.2 & 60 & 60 & OK \\
\hline 2 & 3000 & 7 & 28 & 14.4 & 60 & 60 & OK \\
\hline 1 & 4300 & 3.4 & 13.6 & 13.6 & 86 & 86 & OK \\
\hline
\end{tabular}

\section{PERHITUNGAN STRUKTUR PRIMER}

\section{A. Link}

Balok link direncanakan menggunakan profil WF $400 \times$ $200 \times 8 \times 13$. Hasil dari output program bantu struktur diperoleh gaya dalam sebesar:

$$
\begin{aligned}
\mathrm{e} & =100 \mathrm{~cm}<1,6 . \mathrm{Mp} / \mathrm{Vp}=117.02 \mathrm{~cm} \\
\alpha \quad & =0,024 \mathrm{radian}<\alpha \text { maks }=0,08 \text { radian } \\
\mathrm{Vu} & =35905.7 \mathrm{~kg}<\varnothing \mathrm{Vn}=41188.4 \mathrm{~kg}
\end{aligned}
$$

Untuk pengaku dengan panjang link $<1,6$. Mp / Vp, harus direncanakan memiliki pengaku antara. Untuk $\alpha=$ 0,03 radian maka:

$$
\begin{aligned}
S & =336-\left(\frac{0,024-0,02}{0,08-0,02}\right) \cdot(336-160) \\
& =324.27 \mathrm{~mm}=32.4 \mathrm{~cm}
\end{aligned}
$$

Dipasang pengaku antara dengan jarak $25 \mathrm{~cm}$.

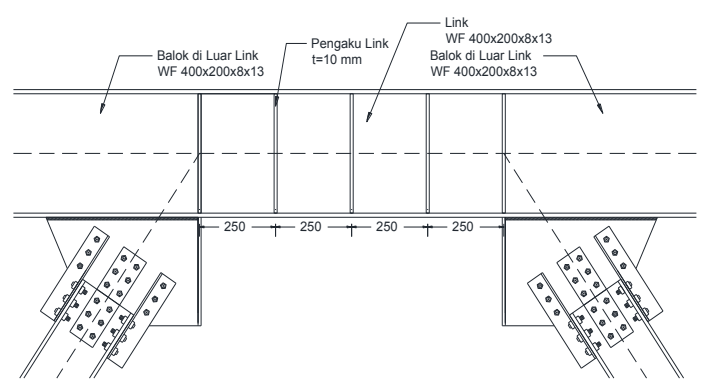

Gambar 5. Elemen Link dan Pengaku

\section{B. Balok diluar Link}

Balok link direncanakan menggunakan profil WF $400 \times$ $200 \times 8 \times 13$. kuat perlu balok yang terletak diluar link harus ditentukan berdasarkan gaya- gaya yang ditimbulkan paling tidak 1,1 kali kuat geser nominal link sebesar Ry.Vn [6].

Kontrol interaksi geser lentur yang terjadi:

$$
\begin{gathered}
\frac{M u}{\emptyset \cdot M n}+0,625 \frac{V u}{\emptyset \cdot V n} \leq 1,375 \\
1.369 \leq 1,375 \quad \ldots \text { OK }
\end{gathered}
$$

\section{Bressing}

Bressing direncanakan menggunakan profil WF 200 $\times 200 \times 9 \times 14$. Berdasarkan Pasal 15.13.6.1, kuat kombinasi- aksial- dan lentur perlu pada batang bresing harus sebesar 1,25 Ry Vn [6].

$$
\begin{aligned}
\mathrm{Vu} & =1,25 . \mathrm{Ry} . \mathrm{Vn} \\
& =1,25 \times 1,5 \times(0.6 \times 2549.29 \times(402 \times 1.3) \times 0.8) \\
& =85809.1 \mathrm{~kg} \\
\mathrm{Pu}_{\text {tekan }} & =\mathrm{Pu}_{\text {tarik }}=\frac{V_{u}}{\sin \alpha}=\frac{85809.1}{0.832}=103129.7 \mathrm{~kg}
\end{aligned}
$$

Bressing tekan

$$
\begin{aligned}
& P_{\text {max }}= 1.1 \cdot R y \cdot F_{y} \cdot A g / \omega \\
&= 1.1 \times 1.5 \times 2549.29 \times 135 / 1.34 \\
&= 153686.6 \mathrm{~kg} \\
& \phi_{c} P_{n}= 0.85 \times 153686.6=130633.6 \mathrm{~kg} \\
& \phi_{c} P_{n}> P u=103129.7 \mathrm{~kg} \ldots \mathrm{OK} \\
& \text { Bresing tarik } \\
& N_{n}= F_{y} \cdot A e=2549.29 \times 50.72 \\
&= 212065.4 \mathrm{~kg} \\
& \phi_{c} N_{n}= 0.75 \times 212065.4=159049 \mathrm{~kg} \\
& \phi_{c} N_{n}>P u \\
& 159049 \mathrm{~kg}>103129.7 \mathrm{~kg} \ldots \mathrm{OK}
\end{aligned}
$$

\section{Balok Induk}

Balok induk direncanakan menggunakan profil WF $300 \times$ $200 \times 7 \times 10$. Dari output program bantu struktur diperoleh gaya dalam yang dipakai dalam desain adalah:

$\mathrm{Mu}=5302.3 \mathrm{kgm}<\varnothing \mathrm{M}_{\mathrm{n}}=16542.3 \mathrm{kgm} . . \mathrm{OK}$

$\mathrm{Vu}=4613.17 \mathrm{~kg}<\varnothing \mathrm{Vn}=27945.3 \mathrm{~kg} \ldots . \mathrm{OK}$

$\mathrm{f}^{\circ}=0.085 \mathrm{~cm}<\mathrm{f}_{\mathrm{ijin}}=1.667 \mathrm{~cm} \ldots \mathrm{OK}$ 


\section{E. Kolom}

Perhitungan kolom dihitung sebagai elemen komposit. Kolom direncanakan menggunakan profil HSS $400 \times 400 \times$ 14 dengan kontrol kuat nominal penampang sebagai berikut:

Rumus Interaksi [7]:

$$
\frac{P u}{\varphi P n}=0,586>0,2 \rightarrow \text { Interaksi } 1
$$

Kontrol Interaksi "Balok - Kolom"

$$
\begin{aligned}
& \frac{P_{r}}{\emptyset P_{n}}+\frac{8}{9}\left(\frac{M_{r x}}{M_{c x}}+\frac{M_{r y}}{M_{c y}}\right) \leq 1,0 \\
& 0.586+\frac{8}{9}\left(\frac{18139.62}{67377.73}+\frac{6662.56}{67377.73}\right) \leq 1,0
\end{aligned}
$$

$0.949<1 \ldots$.OK

Hasil seluruh perhitungan struktur primer akan disajikan pada tabel 8 .

Tabel 8

Hasil Perhitungan Struktur Primer

\begin{tabular}{cc}
\hline \hline Elemen & Dimensi \\
\hline Link X & WF $400 \times 200 \times 8 \times 13$ \\
Link $Y$ & WF $400 \times 200 \times 8 \times 13$ \\
Balok Diluar LinkX & WF $400 \times 200 \times 8 \times 13$ \\
Balok Diluar LinkY & WF $400 \times 200 \times 8 \times 13$ \\
Bresing Arah X & WF $200 \times 200 \times 9 \times 14$ \\
Bresing Arah Y & WF $200 \times 200 \times 9 \times 14$ \\
Balok Induk Memanjang & WF 300 $200 \times 7 \times 10$ \\
Balok Induk Melintang & WF 300 \\
Kolom & HSS $400 \times 400 \times 14$ \\
\hline \hline
\end{tabular}

\section{PERENCANAAN SAMBUNGAN}

\section{A. Sambungan Struktur Sekunder}

Pada perencanaan sambungan, direncanakan baut dengan mutu BJ50 dan pelat penyambung profil siku dengan mutu BJ41.Baut direncanakan hanya memikul beban geser yang berasal dari struktur sekunder. Perhitungan sambungan dianggap sebagai sendi. Hasil perhitungan sambungan struktur sekunder terlampir pada tabel 9.

Tabel 9 Sambungan Struktur Sekunder

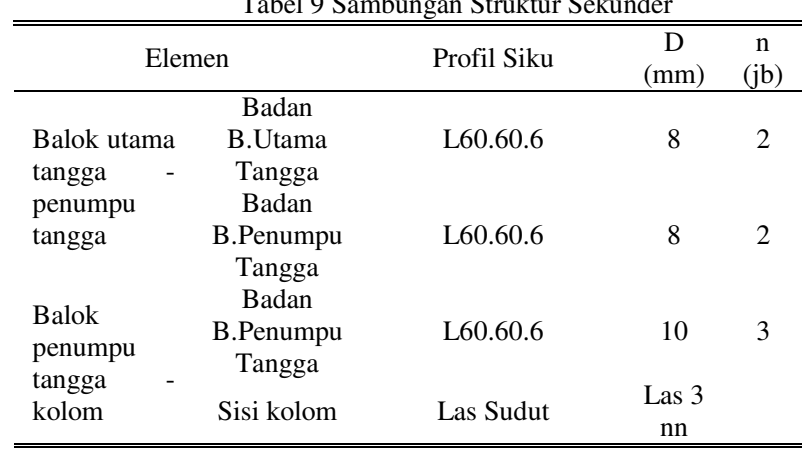

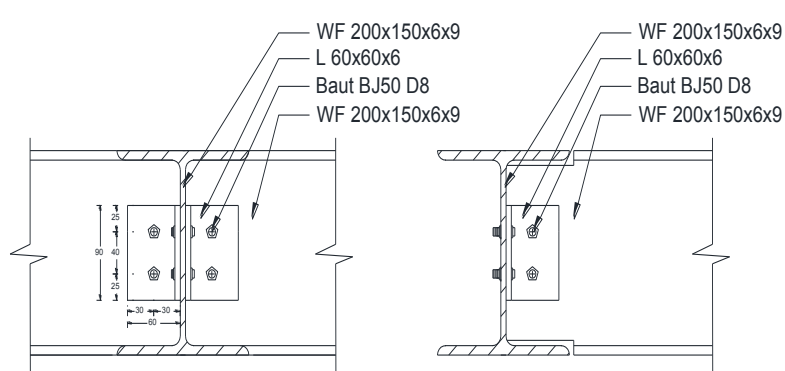

Gambar 6. Sambungan Balok Utama Tangga dengan Penumpu Tangga

\section{B. Sambungan Struktur Primer}

Pada perencanaan sambungan, direncanakan baut dengan mutu A325 dan A490, Mutu las $\mathrm{FE}_{70 \mathrm{xx}}$ dan $\mathrm{FE}_{110 \mathrm{xx}}$ dan pelat penyambung mutu BJ-41. Sambungan pada struktur primer direncanakan dengan sambungan kaku (rigid connection) dimana sambungan memikul beban geser $\mathrm{Pu}$ dan momen $\mathrm{Mu}$. Hasil perhitungan sambungan struktur primer tersaji pada tabel 10 .

Tabel 10.

Sambungan Struktur Primer

\begin{tabular}{ccccc}
\hline \multicolumn{5}{c}{ Sambungan Struktur Primer } \\
\hline $\begin{array}{c}\text { Elemen } \\
\text { badan } \\
(\mathrm{mm})\end{array}$ & $\begin{array}{c}\mathrm{n} \\
\text { badan } \\
\text { (buah) }\end{array}$ & $\begin{array}{c}\mathrm{D} \\
\text { sayap } \\
(\mathrm{mm})\end{array}$ & $\begin{array}{c}\mathrm{n} \\
\text { sayap } \\
\text { (buah) }\end{array}$ \\
\hline $\begin{array}{c}\text { Balok diluar Link X dan } \\
\text { Kolom }\end{array}$ & 12 & 4 & 20 & 24 \\
$\begin{array}{c}\text { Balok diluar Link Y dan } \\
\text { Kolom }\end{array}$ & 12 & 4 & 20 & 24 \\
$\begin{array}{c}\text { Bresing dan Balok } \\
\text { Balok Induk dan Kolom }\end{array}$ & 12 & 6 & 12 & 12 \\
Antar Kolom & 12 & 4 & 20 & 20 \\
Kolom - Base Plate & T Plat = & $\begin{array}{c}\text { Las tumpul sudut 1,6 cm } \\
\text { mm }\end{array}$ & $\begin{array}{c}\mathrm{n} \\
\text { angkur }\end{array}$ & $8 \mathrm{M} 20$ \\
\hline \hline
\end{tabular}

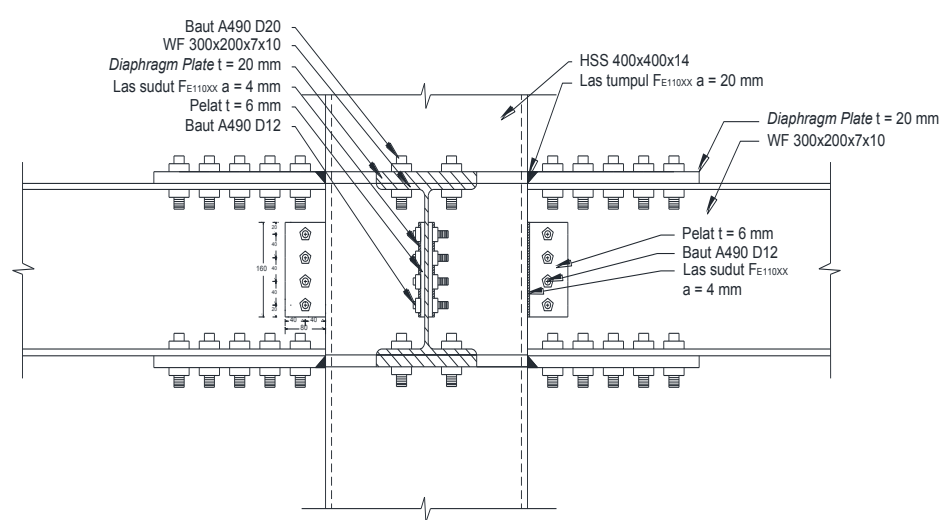

Gambar 7. Sambungan Kolom dan Balok Induk. 


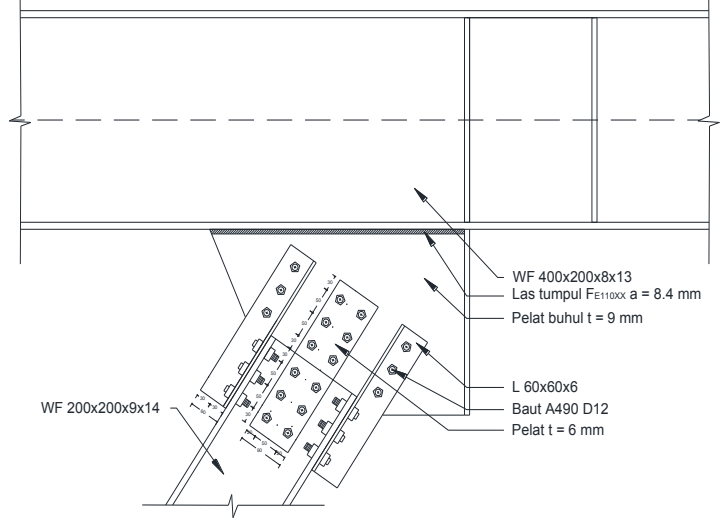

Gambar 7. Sambungan Bresing dan Balok.

\section{PERBANDINGAN BERAT MATERIAL SISTEM STRUKTUR}

Berat material struktur baja dengan SRPE (Sistem Rangka Pengaku Eksentris), dan sistem STF (Staggered Truss Frames) dihitung berdasarkan perencanaan pada studi.

Tabel 11.

Berat Total Struktur SRPE dan STF

\begin{tabular}{|c|c|}
\hline \multicolumn{2}{|c|}{ SRPE } \\
\hline Lantai & $\begin{array}{c}\text { Berat } \\
\text { (kg) }\end{array}$ \\
\hline 1 & 103356.1 \\
\hline 2 & 77060.0 \\
\hline 3 & 77060.0 \\
\hline 4 & 77060.0 \\
\hline 5 & 77060.0 \\
\hline 6 & 77060.0 \\
\hline 7 & 77060.0 \\
\hline 8 & 77060.0 \\
\hline 9 & 77060.0 \\
\hline 10 & 77060.0 \\
\hline 11 & 77060.0 \\
\hline 12 & 77060.0 \\
\hline 13 & 77060.0 \\
\hline Atap & 77060.0 \\
\hline Total Struktur & 1105135.74 \\
\hline
\end{tabular}

\begin{tabular}{|c|r|}
\hline \multicolumn{2}{|c|}{ STF } \\
\hline 1 & $\begin{array}{c}\text { Berat } \\
\text { (kg) }\end{array}$ \\
\hline 2 & 86748.7 \\
\hline 3 & 63750.8 \\
\hline 4 & 50265.2 \\
\hline 5 & 50265.2 \\
\hline 6 & 50265.2 \\
\hline 7 & 50265.2 \\
\hline 8 & 50265.2 \\
\hline 9 & 50265.2 \\
\hline 10 & 50265.2 \\
\hline 11 & 50265.2 \\
\hline 12 & 50265.2 \\
\hline 13 & 50265.2 \\
\hline Atap & 50265.2 \\
\hline Total Struktur & 762936.90 \\
\hline
\end{tabular}

Berat total struktur utama sistem rangka pengaku eksentris lebih besar dari berat total struktur utama sistem staggered truss frames dengan seleisih sebesar 342198.84 $\mathrm{kg}=342.2$ ton

\section{PERHITUNGAN STRUKTUR BAWAH}

\section{A. Pondasi Tiang Pancang}

Pondasi yang digunakan pada perencanaan gedung perkantoran berasal dari tiang pancang beton (Concrete Pile) dengan penampang bulat berongga (Round Hollow) dari produk dari PT. WIKA Beton dengan spesifikasi adalah sebagai berikut:

Perhitungan pondasi dalam berdasarkan rumus [8]. Daya dukung ijin dari satu tiang pancang yang berdiri sendiri adalah

$$
\begin{aligned}
\mathrm{PV} & =\frac{V}{n}+\frac{M_{x} y}{\sum y^{2}}+\frac{M_{y} x}{\sum x^{2}} \\
& =\frac{413328.47}{6}+\frac{13499.92 \times 1.2}{5.76}+\frac{13464.7 \times 0.6}{2.16} \\
& =75440.756 \mathrm{~kg} \\
& =75.44 \text { ton }<\mathrm{P}_{\mathrm{ijji}} \text { grup }=94.697 \text { ton } . . . \mathrm{OK}
\end{aligned}
$$

\section{B. Perencanaan Poer}

Poer dikontrol terhadap geser pons yang terjadi. Untuk penulangan lentur, poer dianalisis sebagai balok kantilever dengan perletakan jepit pada kolom. Dan beban yang bekerja adalah beban terpusat di tiang kolom yang menyebabkan reaksi pada tanah dan berat sendiri poer. Perhitungan tulangan berdasarkan rumus [9].

Tulangan tarik yang dibutuhkan :

- Penulangan Arah X

$$
\begin{aligned}
& \mathrm{As}_{\text {perlu }}=\rho \times \mathrm{b} \times \mathrm{d}^{\prime} \\
& =0.0018 \times 3600 \times 887.5=5751 \mathrm{~mm}^{2} \\
& \mathrm{n}=\frac{\mathrm{As}_{\text {perlu }}}{\mathrm{As}}=\frac{5751}{490.87}=11.7158 \approx 12 \mathrm{buah} \\
& \mathrm{s}=\frac{(3600-2 \times 75-25)}{(12-1)}=306.818 \mathrm{~mm} \\
& \mathrm{~s}_{\text {pakai }}=300 \mathrm{~mm} \\
& =0.002 \times 2400 \times 912.5=4446.24 \mathrm{~mm}^{2} \\
& \mathrm{n}=\frac{\mathrm{As}_{\text {perlu }}}{\mathrm{As}}=\frac{4446.24}{490.87}=9.06 \approx 10 \mathrm{buah} \\
& \mathrm{s}=\frac{(2400-2 \times 75-25)}{(10-1)}=247.22 \mathrm{~mm} \\
& \mathrm{~s}_{\text {pakai }}=240 \mathrm{~mm}
\end{aligned}
$$

\section{Perencanaan Kolom Pedestal}

$$
\begin{aligned}
\mathrm{As}_{\text {perlu }}= & \rho \times \mathrm{b} \times \mathrm{d}, \\
& =0.0116 \times 700 \times 640=5196.8 \mathrm{~mm}^{2}
\end{aligned}
$$

Digunakan tulangan utama 20D20 (dipasang merata 4 sisi)

$$
\text { As }=6283.185 \mathrm{~mm}^{2}>\mathrm{As}_{\text {perlu }}=5196.8 \mathrm{~mm}^{2} \ldots \mathrm{OK}
$$

\section{KESIMPULAN DAN SARAN}

\section{A. Kesimpulan}

Berat total material struktur utama pada perencanaan modifikasi apartemen Purimas Surabaya menggunakan sistem rangka pengaku eksentris didapatkan 1105.136 ton, sedangkan pada modifikasi menggunakan sistem staggered truss frames didapatkan 762.937 ton. Hal tersebut menunjukkan bahwa berat material struktur utama pada modifikasi menggunakan sitem staggered truss frames lebih ringan sebesar 342.2 ton.

\section{B. Saran}

Diharapkan dilakukan studi yang mempelajari tentang perbandingan perilaku antara system struktur SRPE dengan STF lebih dalam sehingga dapat menjadi dasar pertimbangan pemilihan alternatif sistem penahan gempa pada perencanaan struktur bangunan baja

\section{DAFTAR PUSTAKA}

[1] O. Aydan, "Seismic and Tsunami Hazard Potential in Indonesia with a special emphasis on Sumatra Island," J. Sch. Mar. Sci. Technol., vol. 6, no. 3, pp. 19-38, 2008.

[2] M. Bruneau, C. M. Uang, and R. Sabelli, Ductile Design of Steel Structures. USA: Mc Graw Hill, 1998.

[3] Wahyuni, Isdarmanu, and Irawan., "Pemakaian Sistem Staggered Truss Framing (STF) sebagai penahan beban gempa pada Rumah Susun," Surabaya, 2012.

[4] X. Zhou, Y. He, L. Xu, and Q. Zhou, “Thin-Walled Structures. Experimental Study and Numerical Analyses on Seismic Behaviors of Staggered-Truss System under Low Cyclic Loading," 2008.

[5] Badan Standarisasi Nasional, "SNI 1726:2012 Tata Cara 
Perencanaan Ketahanan Gempa Untuk Bangunan Gedung," Jakarta, 2012

[6] Badan Standardisasi Nasional, "SNI 1729-2015: Spesifikasi untuk Bangunan Gedung Baja Struktural,” Jakarta, 2015.

[7]

Badan Standarisasi Nasional, "SNI 03-1729-2002 Tata Cara Perencanaan Struktur Baja Untuk Bangunan Gedung," Jakarta,
2002.

[8] H. Wahyudi, Daya Dukung Pondasi Dalam. Surabaya: Jurusan Teknik Sipil FTSP - ITS, 1999.

[9] Badan Standardisasi Nasional, "SNI 2847-2013: Persyaratan beton struktural untuk bangunan gedung," Jakarta, 2013. 